\title{
A RARE INTERESTING CASE OF HUGE OMENTAL CYST MIMICKING AN OVARIAN CYST
}

\author{
B. Venkateswara Rao ${ }^{1}$
}

\section{HOW TO CITE THIS ARTICLE:}

B. Venkateswara Rao. "A Rare Interesting Case of Huge Omental CYST Mimicking an Ovarian CYST". Journal of Evolution of Medical and Dental Sciences 2014; Vol. 3, Issue 12, March 24; Page: 3220-3222,

DOI: $10.14260 /$ jemds/2014/2270

INTRODUCTION: Omental cysts are very rare and usually present with painless abdominal swelling. An incidence of about 1 in 105000 to 140000 cases is reported in the literature ${ }^{1}$. Omental cysts are 3 to 10 times rare than the mesenteric cysts. Ovarian cyst is the commonest ovarian mass in the gynecology outpatient department. A very rare huge Omental cystic mass is diagnosed provisionally as ovarian cyst and laparotomy was done. Our hospital is a 500 bedded rural based teaching hospital attached to a Government Medical college at Anantapuramu, Andhra Pradesh.

KEYWORDS: Omental cyst; Ovarian Cyst.

CASE REPORT: A 52 year old post-menopausal woman, para 3 was admitted in our hospital with a complaint of distention of abdomen since 7 months. History of decreased appetite since 6 months. On examination she is thin built and with mild anemia. Per abdomen - A huge intra-abdominal cystic mass of about 32 weeks size occupying all over the abdomen, with restricted mobility.

Per speculum - Cervix pushed down and appears healthy. Per vagina - Uterus is atrophic and separately felt and the cystic mass is felt through all the fornices. Our provisional diagnosis was made as Ovarian mass.

The following investigations were done - Hb- 9.2 gms\%, Blood group - A+ve, Blood urea - 28 mgs, Serum creatinine - 0.6 mgs, BT - 2'30", CT - 4'00”, “CA 125” - 28.7 u/ml (reference value less than $35 \mathrm{u} / \mathrm{ml}$ ). USG shows - Entire abdomen is occupied with the huge cystic swelling with multiple thick internal septations, no evidence of ascites. Uterus is atrophied.

Right and left ovaries not visualized. CT scan shows - The entire abdomen is occupied with a huge multiloculated cystic swelling with internal septations. X-ray chest P-A view- Normal. Cardiac status was stable.

Laparotomy was done. Laparotomy shows a huge multiloculated cystic mass occupying the whole abdomen. Flimsy peritoneal adhesions were present. The mass was delivered out with difficulty (fig. 1). The Uterus, both fallopian tubes and ovaries were separate from the mass and appears normal. Surgeon was called for the help.

The cyst was found arising from the greater Omentum (fig. 2) and the same was removed. Remaining peritoneal surface was normal. Bowels and the Mesentery appear normal. Liver and the under surface of the diaphragm were normal. The cyst weighed about 8 kgs (fig. 3).

The mass was sent for histopathological examination. The histopathological examination showed mostly lymphoid tissue with reactive hyperplasia and increased vascularity. No evidence of malignancy or granuloma noted.

DISCUSSION: Omental cyst is a rare intra-abdominal mass, mostly derived from lymphatic tissue. ${ }^{2}$ It occurs in all age groups. Mostly the Omental cysts are of benign nature. ${ }^{3}$ Malignant change has been 
reported but is uncommon. A complete resection is mandatory because of high incidence of relapse. ${ }^{4}$ Mesenteric and Omental cysts are the differential diagnosis of the Ovarian mass.

CONCLUSION: Omental cysts are the rare cysts in the abdomen. A high index of suspicion is required to make a clinical diagnosis. The clinical picture of the huge Omental cyst appears like a malignant Ovarian cyst in this woman. The prognosis for the omental cysts are usually good when compared to the ovarian cysts in a post-menopausal women. ${ }^{5}$

\section{REFERENCES:}

1. Berger L Rothenberg RE. Cysts of the Omentum, Mesentery and Retroperitoneum. Surgery 1939; 5: 522.

2. Gairdner WT. A remarkable cyst in the Omentum. Trans Path Soc London. 1852; 3.185 - 91.

3. Tan JJ, Tan KK, Chew SP. Mesenteric cysts: an institution experience over 14 years and review of literature. World J Surg. 2009; 33:1961.

4. Walker AR, Putham TC. Omental, Mesenteric and Retroperitoneal cyst. A clinical study of 33 new cases. Ann Surg. 1973; 178: 13-19.

5. Hardin WJ, Hardy JD. Mesenteric cysts. Am J Surg 1970; n 119:640.

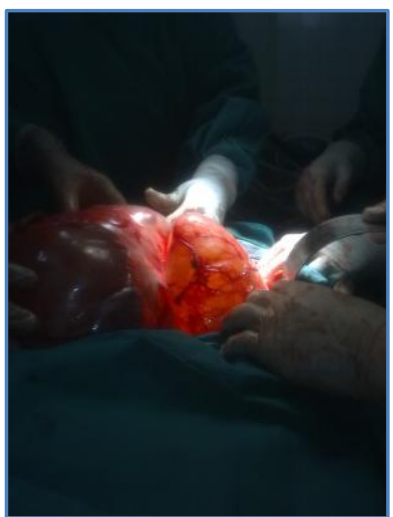

Fig. 1: Omental cyst delivered out

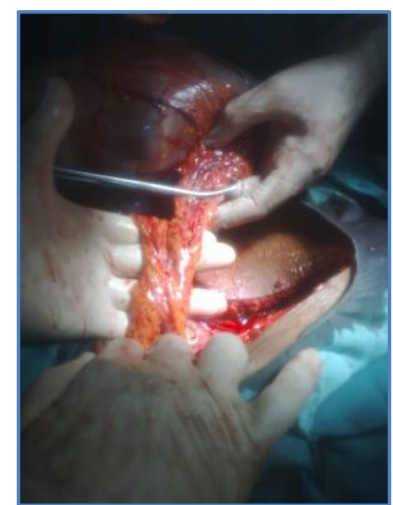

Fig. 2: Omental attachment of the cyst

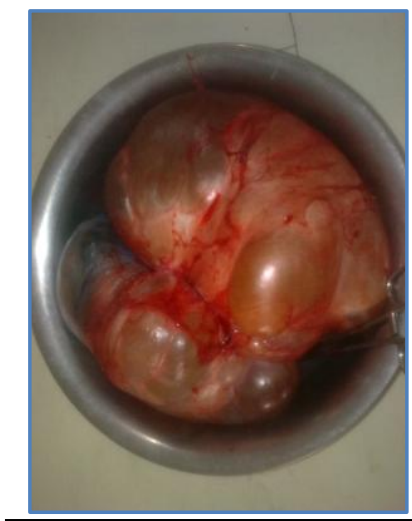

Fig. 3: Omental cyst 


\section{CASE REPORT}

\section{AUTHORS:}

1. B. Venkateswara Rao

\section{PARTICULARS OF CONTRIBUTORS:}

1. Associate Professor, Department of Obstetrics and Gynaecology, Government Medical College/Government General Hospital, Anantapuram, Andhra Pradesh.

\section{NAME ADDRESS EMAIL ID OF THE CORRESPONDING AUTHOR:}

Dr. B. Venkateswara Rao,

H. No. 27-8-4,

$4^{\text {th }}$ Line, Kannavarithota,

Guntur - 522004,

Andhra Pradesh.

E-mail: birra_venkat@yahoo.com

Date of Submission: 15/02/2014.

Date of Peer Review: 17/02/2014.

Date of Acceptance: 01/03/2014.

Date of Publishing: 24/03/2014. 